Paper for International Journal of Social Research Methodology: Theory and Practice (Special issue on Longitudinal Qualitative Methods, forthcoming August 2003)

\title{
Interpretive claims and methodological warrant in small-number qualitative, longitudinal research
}

\section{Lyn Yates}

Address for Correspondence:

Professor Lyn Yates

Faculty of Education

University of Technology, Sydney

PO Box 222

Lindfield NSW 2070

Australia.

lyn.yates@uts.edu.au

fax [int] 61295145620

ph [int] 61295145230 


\begin{abstract}
This article discusses issues of methodological warrant in a qualitative, longitudinal study that works with only a small number of subjects. The 12 to 18 Project was designed to contribute to research on gender, class and schooling. The rationale for a design using only 26 students spread between 4 schools is explained. It is argued that even with small number research issues of selection and comparison are important but that emphasis on techniques of data-treatment and comparison is misplaced. It is argued that the meaningfulness and contribution of studies of this type lie in multiple acts of design, comparison, reflexive interpretation and dialogue with the broader field, and that the more that such studies emphasize technical analytic procedures, the more they undermine their warrant to be anything other than a report on a small sample. Illustrations of interpretations of the data and from the data are given.
\end{abstract}


Every act of research is simultaneously empirical (it confronts the world of observable phenomena) and theoretical (it necessarily engages hypotheses about the underlying structure of relations that observations are designed to capture)

(Bourdieu and Wacquant 1992,p.35)

Coding is a questionable step to take with qualitative data...

(Hollway and Jefferson 2000, p.109)

Case study cannot claim its authority; it must demonstrate it.

(Kemmis 1980, p.109)

The issue of educational inequalities and the difference that different schools make is one of the most worked-over fields of educational research. Researchers have worked with large input-output data-bases of many different types, have studied classroom processes, have deconstructed curriculum, have undertaken ethnographic studies of groups of girls and boys from different class or ethnic backgrounds. Some eight years ago, Julie McLeod and I began a study that was intended to make some contribution to this field. The 12 to 18 Project $^{1}$ set out to follow twenty-six 12 year olds through every year of their secondary schooling and beyond it until they were 18. The study is longitudinal, qualitative, small number. In this article I want to discuss what might be seen as issues of methodological warrant in relation to this study. How can particular stories of individuals be seen to carry weight as research about 'gender' or 'class' or 'schooling' when they are stories of only a few people, told in particular circumstances, to particular researchers? And what methodological steps and acts are appropriate to justify the claims that we try to construct on the basis of such a project?

We constructed this study around a relatively small number of subjects for reasons that were both theoretical and pragmatic. Our specific take on the inequalities issue was to attempt to understand subjectivity and biography in interaction with particular schools. Unlike many ethnographic studies of class and schooling, and unlike the well-known 7 Up film series, we wanted to avoid conflating 'habitus' of family and school (Yates 2000a). We wanted to be able to look at children from different backgrounds in the same school, and from similar

\footnotetext{
${ }^{1}$ The 12 to 18 Project was undertaken between 1993 and 2000. It was funded by a series of grants from the Australian Research Council, with additional support from La Trobe University, Deakin University and the University of Technology, Sydney. See also the article by McLeod in this issue.
} 
backgrounds at different schools, so chose four schools as our basis, with six to eight students in each. Unlike many sociological studies of schooling and gender, we wanted an opportunity to see the individual and their development over an extended period of their adolescent years (McLeod 2000). But, immersed in understandings about the constructed nature of the interview as event and as representation, wanting to be closely and reflexively engaged in both tasks and their inter-relationship, we also needed the study to be of sufficiently restricted size that all interviewing and analysis could be done by ourselves together, rather than something we sub-contracted and reviewed at a distance. (McLeod and Yates 1997). So, although this is not a small study (seven years and over 350 lengthy interviews), in the context of education inequalities research it is a study of a small number of people.

In the light of the much discussed crisis of representation in the social sciences, the epistemological stance from which we were working was an acceptance that what we were producing was certainly shaped by us, was not the only 'truth' that could be constructed about the young people we studied, and that the processes of production of the study require ongoing reflexive attention. But equally, as researchers located in the field of Education, we were trying to design an approach where what we constructed could not be easily seen as an arbitrary story, or as only the story of the 26 individuals we happened to interview. What we were trying to do was to take seriously the need to analyse the interview as a construction, as situated, as the production of one embodied, aged human subject talking to other embodied, aged human subjects in a particular location, the school. (McLeod and Yates 1997) But what we were also trying to do was to find ways of engaging with the claims that other researchers educationists, policy-makers, the press make about how young people 'are', or what schools 'do'. (Yates 2001)

The point of dealing with small numbers of subjects in a lot of detail is to see specificity and context in some fine grain; the problem of dealing with small numbers is the potential overreading we bring to it, either in what we make of those individual stories, or in the claims we make from them about our big issues. These are dilemmas that confront us both in doing the research, and in presenting and justifying our work in the broader debates of our professional field. In this article I want provide some argument and illustration that the methodological warrant for this work has to be constructed by the researchers in ongoing and multiple acts of design, comparison, dialogue, reflexive critique and interpretation. I argue that even with small number research, issues of selection and comparison are important. But I also argue that 
an emphasis on techniques of data-treatment and comparison is misplaced. The meaningfulness and potential contribution of studies of this type lie in acts of interpretation and dialogue with the broader field. The more such studies move to mimic factor analysis procedures, the more they undermine their claim to be any more than a report on 'a small sample’.

'The invention of the study'

In much longitudinal research, even that using qualitative interviewing, the implicit metaphor for research activity is still that of experimental science, of controlled comparison and manipulation of variables. With national data-bases, large-scale cohorts, inter-country comparison, there is some recognition of the problem of getting samples which are strictly equivalent, but that is largely treated as an error factor we have to take account of within the controlled comparisons. My own initial training however was as a historian. A historian is required to construct an overall story or narrative or interpretation or way of seeing a whole range of material. Doing historical research requires engaging with what types of thinking and ideas we bring to acts of analysis, and to claims that something has produced or shaped something else; what means we need to take to persuade readers that we have dealt adequately with the whole range of possible texts, or that we have dealt in defensible ways with the representation of a particular text. So I come to educational research with a belief in thinking about the empirical as 'evidence' but evidence in which the further question 'evidence of what?' is always a part of the researcher's activity, is itself a task to be investigated, and in which closure is not assumed to be possible.

In the case of broad social theory (eg Bourdieu 1998; Putnam 2000) and in contemporary reflections on the micro-dynamics of an interview (eg Hollway 1997; Maclure 1993), it is easy to see that the object of study is constructed rather than fixed, and that a range of appropriate tools or methods or sources is invented and displayed for making claims about the object of study. But the same issues of construction and constructing justification apply to all studies. In the 12 to 18 Project, the issue of whether 26 students, or four schools, or the questions we asked, or the number of engagements we had is 'enough', or whether what we make of our study is convincing, is not pre-given nor resolvable by methodological formulae. The justification must be made within the study itself, and is inherent in the 'invention' of what the study is. (The term ‘invention' here is borrowed from Kemmis’s (1980) evocative 
argument about the epistemological basis of case-study research as being 'the imagination of the case and the invention of the study'.)

The uses of comparison in a small-number, qualitative, research project:

In the 12 to 18 Project, we based our study in four school sites (one elite, one disadvantaged, and two 'middle' high schools), two in the metropolitan city, two in a provincial town, and with roughly numbers of girls and boys. We selected subjects with regard to including 'students from different backgrounds at the same school, and from similar backgrounds at different schools'. This might seem to mimic the quasi-experimental structuring that is more commonly found in large-number research designs - but we have only six to eight students at each school, and similarly small numbers that might represent different kinds of class or ethnic backgrounds, especially in combination with gender. It might therefore be argued that for any type of comparison, the numbers involved are so small as to make the activity meaningless. In contrast, I want to argue that the opportunities for a large range of different types of selection and comparison that we set up in this study is an important part of why our study, notwithstanding its small numbers, is a significant one which is more than simply the stories of the 26 individuals. But I also want to argue that the 'comparison' which grounds the study is an interpretive comparison (or rather series of comparisons), very different from the factor-analysis comparisons set up in quasi-experimental studies.

A starting point in the 12 to 18 Project was to understand schooling and inequality through an approach that would construct different insights than existing data-bases, classroom studies and ethnographies. One part of this was to talk to the same young person twice a year over eight years, to get a fuller sense of their agendas, interests, relationship to family and school, consistencies and changes. Unlike time-lapse and cohort studies, our longitudinal interest was not in average changes between different demographics, but to see how particular individuals lived the changes, to explore what the processes look like. But if we find, as we did, students emphasizing different themes, or developing different choices and orientations by the end of the study, on what basis do we claim we are seeing a working out of gendered processes, or class ones, or school effects? As Bourdieu and Wacquant (Bourdieu and Wacquant 1992) say, the theorizations we call on when we interpret such texts are never wholly given by those texts, and clearly the claims that we and others make, the ideas that we have, draw on the world of literature and previous research that we work from. But the adequacy of the empirical evidence itself is also an issue. 
What we set up in this study was the opportunity for ongoing comparison in terms of the types of broad issues we were interested in exploring: opportunities to follow and compare what is said by an individual over an extended time; opportunities to partially detach demographic and school by comparing like in different contexts and vice versa. When we asked a question such as 'Do you feel optimistic, or pessimistic about your future?' or 'What do you think causes unemployment?', we can compare how these questions are answered by girls compared with boys, or by boys of middle-class background compared with those of working-class background, or by girls of middle-class background at an elite private school and those of similar background at a high school; and we can also look at whether the answers form more similar patterns when considered by school as compared with by the background or gender of the students. But our epistemological assumptions in doing this are not the same as in survey-based research. Our numbers are small, and a one-off comparison proves little.

What is meaningful is to build up a comparison based on detailed engagement with a subject (and a school context) over time. As I will illustrate in the later examples, the comparison here is not a reading-off of 'findings' guaranteed by adequate sample construction and computer-based technical methods. The object of comparison is itself constructed of interpreted texts, but comparison is also used in the process of interpreting the texts (the subjects, the schools): it is always a process of moving back and forth between whole and parts, between different extracted comparisons. And the process of interpretation includes reflexive attention to the context of production of our data, including the temporary context of our embodied interview (for which we were present, and have video data as well as transcripts). (See McLeod and Yates 1997 and forthcoming, for illustrations.)

What we are setting up in the comparative design and method of the project is not a replication of 'controlled comparison' in the ways that that is done with large-scale studies, but the setting up of opportunities to think self-critically about the attributions we are making about the meaning of the texts in relation to the larger education issues which are the context of our study. (Yates 2001)

Hollway and Jefferson (Hollway 2000, p.109) discuss similar concerns about processes of dealing with interview data, and the foundations of theorization, in their own study of crime 
and anxiety, a study also dealing with a relatively small number of subjects and with a broader theoretical agenda. They write

Coding is a questionable step to take with qualitative data based on principles of preserving meaning within biography and social context.

They commented that 'the more we subdivided categories to be sensitive to differences, the more these risked fragmentation, thus threatening the whole that gave them their meaning' (p108). Hollway and Jefferson describe processes of trying out different ways of comparing or working with their data: of coding and resisting coding, of trying to theorize pattern while not wiping out the biographical meaning of particular lives which is at the heart of their study. Again, the point is two-fold: that what is being compared is not a transparent or pre-designed given; but that the process of working with empirical data must involve some means of grouping, comparing, building and testing which make sense in terms of the logic and purposes of the particular study.

Advocates of software packages for handling qualitative data, such as NUD*IST (Richards and Richards 1998), and QCA (Rantala and Hellstrom 2001) emphasize that their use as a tool for coding, retrieval and comparison does not undermine hermeneutic reading of interview transcripts and other qualitative texts. In the 12 to 18 Project we have been more wary of the impetus associated with these now commonly used 'tools'. While in principle the researcher controls the types of coding, comparison and readings that are done, and it is possible to work with large chunks of data, the coding possibilities tend to encourage increasingly fine categorizations and uses of data which no longer reads them 'in context'. Our deliberate restriction of our study to a size where we ourselves did all the interviews, and our use of processes of analysis that could build up a picture of an individual over time, as well as look at whole interviews across a particular year, we consider to be important in terms of the integrity of a project which claims to do something different from surveys and snapshots.

Of equal concern with the software packages is not just what is done with them, but how they are increasingly coming to provide the 'warrant' for the quality of the research practice. Claims about meaning, findings, comparison begin to rest on a quantitative and technical logic: that every case was considered in the same way, that the data has been 'thoroughly' searched. This is a different logic, and a different type of contribution than the process of multiple readings, dialogical reflections within and across the interview material and also 
outside it, that we were engaged in, and where the justification of the method and evidence is discursively presented in the interpretive accounts.

\section{Interpretive Claims and one Study}

The 12 to 18 Project is being undertaken in a context that is not a blank slate. Data bases already provide considerable information on what categories of children get what out of school, and on the patterns of retention and achievement that particular schools produce. In this final part of the article, I want to provide brief illustrations of two ways in which we try to bring together our particular qualitative, longitudinal study into dialogue with that work. In the first case, I take school outcomes and the type of picture we build up of what effects are being produced. In the second case, I take one student in our project and show readings that can be done of her experience and from her experience in relation to class, gender and particular school effect. (However one of the disadvantages of detailed qualitative study is that the particulars and the subtleties are important, and not well-served by brief summary. Fuller discussions can be found in publications from the project cited in the reference list.)

\section{Reading across the study: inequalities and school effects}

First, let us consider 'school difference'. We included in our study students at two 'ordinary' high schools, schools which roughly had similar demographic and retention patterns as databases measure these. By the age of 18, we were able to see some differences in the pattern of what students were thinking as well as doing at the two schools. In their first post-school year, the young people from High School A were engaged in a range of vocationally-oriented studies, or in work. They were instrumentally oriented, planning their next steps, talking in ways that indicated a belief in their potency in the world, and that where they would end up was up to them. They had a sense of a competitive world, and the need for hard effort. They were not very sympathetic to matters of race or unemployment. From High School B, at 18, virtually no-one was securely in a vocationally-oriented path: two were still finishing school, two had dropped out of courses and one was thinking of doing so, one was finding herself in a Women's Studies course, another was doing a lower level vocational training than the one he had been aiming for. These young adults talked most about finding themselves, not being sure where they were going, hoping to find out. They were sensitive to social issues of inequality, especially racism. (See Yates 2001; Yates and McLeod 2000b for a more detailed discussion.) 
But in what sense can we talk about a pattern here, or claim to be showing something about 'biographies in interaction with schooling'? It is true that in each school we have closely followed only a handful of different students. But our case is built not by counting but by showing what is happening. For each student we have hours of interview material extending over eight years, including direct and indirect discussions about themselves, their school, other students. The emerging values we point to are not simply literal answers to one question at one point in time, but meanings and consistencies that can be identified in comments made about a whole range of issues. Some of the evidence that builds the case about certain school effects being at work in these outcomes include:

- things that are said over the seven years about what each school emphasizes (in High School A, competitiveness and 'being as good as the private schools'; in High School B, care, diversity, being inclusive, having second chances), that is, 'evidence' produced well before we or they knew what they would be saying at 18;

- a greater diversity in values of students at the beginning of the study than after some time in each school (for example, students from middle-class backgrounds with higher achievement orientations at High School B, who over time became less instrumentalist compared with those of similar backgrounds at other schools);

- the fit (by school group) between the way they answered broad questions on social issues such as unemployment and racism aged 15 and the paths and sense of themselves they were showing at 18;

- showing how different 'measured' outcomes can be part of the same pattern - for example, that the one student who dropped out early at High School A was equally a product of its instrumentalism, competitiveness and lack of attention to 'losers' as were those who ended up vocationally on track.

\section{Interpreting an individual story}

Reading an individual story, inscribing it in terms of gender, class or school processes, involves similar multiple patterns of horizontal and longitudinal comparison, dialogue with the broader literature, comparison with like and unlike stories within the study.

To take an example (see McLeod 2000, Yates 1999, 2000a for other illustrations), one girl, Katie, attends the private school in the study, has a period of rebellion in her middle years, tells us over the eight years about her dreams for the future as well as about her family and her falling-out and remaking of friendships in the present, and at 18 is studying fashion 
design. This is a particular person with particular agendas, making her life in particular circumstances. The research task is to elicit and demonstrate some patterns of broader significance.

One repeated theme that surfaces in many of Katie's interviews is 'being her own person', being an individual, finding out who she is. Coming to this from the research literature on femininity, we look more particularly at how this theme manifests itself in relation to issues of self in relation to others, and in terms of Katie's dreams for her future domestic and public life. In these contexts, Katie exemplifies some of the features of gendered middle-class femininity at this point in history. She dreams of having children while she is young - but at the same time she makes clear she knows (family and friends tell her) this is aberrant for girls of her class today. She says she daydreams about a future marriage and family, but at the same time is full of dreams of more distinctive achievements. She does not want to be like her own mother who is not in paid work.

So, from the literature we draw agendas to take to the texts of Katie's interviews: questions to pose about how she puts certain issues together. but our claims about what class/gender and school effects look like today are further built through readings of the study itself. All the students from Katie's school indicate, directly and indirectly, that they see the school as valuing individuality, being your own person. They all also make clear that they know this means having distinctive achievements, that not all ways of 'being an individual' measure up (Yates 2000a).

These themes of 'being your own person', of establishing your difference, your individuality, are never heard in interviews with the girls at the poorest school in our study (who are more likely to talk about 'taking it as it comes'), and heard only in much more muted fashion in the girls at the middle schools (these girls work towards a vocational future but do not dwell on having to be distinctive). But Katie's themes are heard in each of the other girls we interview at her school, even though their particular stories have their own specificity. One girl at the school, from a less elite class background, gradually moves her aspiration from the ordinary one of being a teacher to the more distinctive one of studying music therapy (McLeod 2000). Another, frustrated with being just outside the circles of wealth and achievement which she sees as dominant in the school, runs away - but does this in a dramatic fashion to a distant place where at 18 she is at university and studying to be a lawyer. So evidence across the 
study, across the other students is used to interpret what Katie is saying, just as her story is part of what is being used to make sense of the study overall.

In reading Katie's story we also give attention to the interview as an event, a relationship between ourselves and Katie in particular circumstance. In one of our interviews, for example, Katie pauses in her story of rebellious behaviour that her parents don't know about to say to my co-researcher who was pregnant in earlier interviews 'I get scared telling you these things, when you have little children.' This is one of a number of examples of the middle-class girls in our study being very attuned to what may be going on in the heads of those they are speaking to. It speaks both of a continuing agenda to take care of others in these girls, notwithstanding the dreams of public achievement; and also high skills of empathy and reflexivity.

In earlier papers (McLeod and Yates 1997; Yates 1999) we have discussed other examples of this self-awareness, and the way it was most evident in middle-class girls: a girl not wanting to let her mathematics teacher know that his explanation was not clear because of how it would affect him and his broader relations with her; an early interview, where a girl talked on about her various dreams of fame and glory and then looked at us and paused and said she'd also like to go and help the people in Somalia.

Noticing these processes is, at least in part, a matter of the theoretical awarenesses we bring to the study. In interpreting them, we engage in implicit dialogue and comparison with the specific different subjects in our study, with the study as a whole, and with research and theorizing outside the study, and in doing so, we engage in a process of inscription: we name them, and thereby locate them in broader patterns of theorization. For example, to name the examples I have summarized here as 'reflexivity' is to give them a positive connotation, to connect what these girls do to the type of self-awareness and ability to self-critique that we ourselves aspire to as researchers. Giving it a more negative connotation, and relating it to earlier theorizations of women's psychology as 'the other', we might name it as 'learning to see yourself primarily through others' eyes'. Or again, influenced by Foucault and Nicholas Rose, we might depict what we noticed as being the imperative to self-monitor, to observe and discipline the self. Whatever it is, our empirical study suggests that it is particularly highly refined in middle class girls today, and whatever it is, it would be quite inadequate to see this as a story that is established by techniques of dealing with our data. The theorizing task is to 
locate the practice that has been noticed convincingly in an array of other observations and arguments. (In this particular project, located against broad issues in schooling and inequalities, my own inscription of these processes has related them to the broader issue of middle class girls and school success. (Yates 1999))

\section{Subjectivity, school difference, and interpretive engagements}

In this article I have been discussing a qualitative and longitudinal study that has attempted to take seriously the complexity of the human subject, and the problem of the constructing and inscribing role of the researcher, but also to work with some more traditional concerns about what would be needed to ground insights into the dimension of gender and class or school effects today. These concerns shaped the key features of the design of the 12 to 18 Project, namely: (i) a selection of schools and subjects which provides opportunities for multiple comparisons and which did not conflate school and social class; (ii) a qualitative and longitudinal approach, to enable some appreciation of particular biographies in particular school contexts; and (iii) the decision that the two principal researchers would do all interviews as well as analytic work in this project. In terms of 'method', what I have been talking about here is not a neat technique (is not a regulated system of steps), in the way that some forms of linguistic discourse analysis, or factor analysis aspire to. I have been trying to demonstrate how the study is 'invented', and to show the paths of theorising and comparison, by which we build up and test out the interpretive engagements of our study, both of our 'data’ and from our data. 


\section{References}

Bourdieu, P. (1998) The State Nobility (Cambridge: Polity Press).

Bourdieu, P. and Wacquant, L. J. D. (1992) An Invitation to Reflexive Sociology (Chicago: University of Chicago Press).

Hollway, W. and. Jefferson, T. (1997) Eliciting narrative through the in-depth interview, Qualitative Inquiry 3(1): 53-70.

Hollway, W. and Jefferson, T. (2000) Doing Qualitative Research Differently: free association, narrative and the interview method (London: Sage).

Kemmis, S. (1980) The imagination of the case and the invention of the study. In H. Simons (ed) Towards a Science of the Singular (University of East Anglia: Centre for Applied Research in Education), pp.89-113.

Maclure, M. (1993) Mundane autobiography: some thoughts on self-talk in research contexts. British Journal of Sociology of Education 14(4): 373 - 384.

McLeod, J. and Yates, L. (1997) Can we find out about girls and boys today, or must we just settle for talking about ourselves. Dilemmas of a feminist, qualitative longitudinal research project. Australian Education Researcher 24(3): 23 - 42.

McLeod, J. 2000 'Schooling and subjectivity in a longitudinal study of secondary students', British Journal of Sociology of Education 21(4): 501-521.

McLeod, J. and Yates, L. (forthcoming) 'Who is "us”? Students negotiating discourses of racism and national identification in Australia', Race, Ethnicity and Education.

Putnam, R. D. (2000) Bowling Alone: the collapse and revival of American community. (New York: Simon \& Schuster).

Rantala, K. and. Hellstrom, E. (2001) Qualitative comparative analysis and a hermeneutic approach to interview data. International Journal of Social Research Methodology 4(2): 87-100.

Richards, L. and Richards, T. (1998) Software for live data? A new stage for qualitative computing. XIV ISA World Congress of Sociology, Montreal.

Yates, L. (1999) How should we tell stories about gender and class in schooling today? In Birkelund, G.E., Broch-Due, A. and Nilsen,A. (ed) Ansvar og Protest: Kjonn, klasse og utdanning i senmoderniteten. (Bergen: University of Bergen Press).

Yates, L. (2000a) Representing 'class' in qualitative research. In J. McLeod and. K. Malone (ed) Researching Youth. (Hobart: Australian Clearinghouse for Youth Research), pp.149-162. 
Yates, L. and McLeod, J. (2000b) Social Justice and the Middle. Australian Education Researcher 27(3): 59-77.

Yates, L. (2001) Selves, social factors, school sites and the tricky issue of 'school effects'". Change: transformations in education 4(2): 15-29. 


\section{University Library}

\section{- M M N E R VA A gateway to Melbourne's research publications}

Minerva Access is the Institutional Repository of The University of Melbourne

Author/s:

Yates, L

Title:

Interpretive claims and methodological warrant in small-number qualitative, longitudinal research

Date:

2003-07-01

\section{Citation:}

Yates, L. (2003). Interpretive claims and methodological warrant in small-number qualitative, longitudinal research. International Journal of Social Research Methodology: Theory and Practice, 6 (3), pp.223-232. https://doi.org/10.1080/1364557032000091824.

Publication Status:

Published

Persistent Link:

http://hdl.handle.net/11343/34738 